Tema: Materiais cerâmicos, compósitos e poliméricos

\title{
ESTUDO DA EFICIÊNCIA DE TECIDOS FOTOPROTETORES UTILIZADOS CONTRA OS EFEITOS NOCIVOS DA RADIAÇÃO SOLAR*
}

\section{Resumo}

Cláudio Orestes de Britto Filho' Juliana Meira de Vasconcelos Xavier ${ }^{2}$ Marcus Vinícius Lia Fook ${ }^{3}$

A exposição excessiva ao sol tem contribuído de forma significativa para o desenvolvimento de catarata, envelhecimento precoce, câncer de pele, agravamento de algumas dermatoses, dentre outras doenças, trazendo impacto negativo sobre a qualidade de vida dos indivíduos. Protetores solares, vestimentas e acessórios são frequentemente utilizados como forma de prevenção para os efeitos nocivos da radiação ultravioleta. No entanto alguns tipos de tecidos não proporcionam proteção suficiente. Novos produtos têxteis, com a incorporação de partículas de filtro solares inorgânicos, tem sido alvo de diferentes observações científicas. Esta pesquisa objetivou avaliar a eficiência de tecidos sintéticos, utilizados como filtro solar, cuja base do material é a poliamida. Os tecidos foram caracterizados pelos métodos de Microscopia Ótica- MO; Microscopia Eletrônica de Varredura-MEV; Espectroscopia por Energia Dispersiva (EDS); Difração de Raios X- DRX; Espectroscopia na Região do Infravermelho com Transformada de Fourier-FTIR e Calorimetria Exploratória Diferencial (DSC). Resultados mostram que com a incorporação da biocerâmica, mostram propriedades relevantes, contra os efeitos nocivos da radiação solar, quando comparados ao tecido sem incorporação da mesma. As roupas protetoras pode ser uma estratégia efetiva na proteção contra os danos causados pela exposição excessiva a radiação solar, durante a exposição a esse tipo de radiação.

Palavras-chave: Radiação solar; Tecido fotoprotetor; Proteção solar.

\section{STUDY ON THE EFFICIENCY OF FABRICS USED AGAINST HARMFUL SUNSCREENS THE EFFECTS OF SOLAR RADIATION}

\section{Abstract}

Excessive sun exposure has contributed significantly to the development of cataracts, premature aging, skin cancer, worsening of some dermatoses, among other diseases, bringing negative impact on the quality of life of individuals. Sunscreens, clothing and accessories are often used in order to prevent the harmful effects of ultraviolet radiation. However some types of fabrics do not provide sufficient protection. New textile products, with the incorporation of particles of inorganic sunscreens, has been the subject of different scientific observations. This research aimed to evaluate the efficiency of synthetic fabrics, used as sunscreen, whose base material is polyamide. The tissues were characterized by the methods of optical microscopy - MO; Scanning Electron Microscopy - SEM; Energy Dispersive Spectroscopy (EDS); X-ray diffraction XRD; Infrared spectroscopy in the region with Fourier transform - FTIR and Differential Scanning Calorimetry (DSC). Results show that with the incorporation of bioceramics, show outstanding properties, from the harmful effects of solar radiation compared to the tissue without incorporating the same. The protective clothing can be an effective strategy in protecting against the damage caused by excessive exposure to solar radiation during exposure to such radiation.

Keywords: Solar radiation; Sunscreen fabric; Sun protection.

Médico, Mestre em Eng. Materiais, UFCG, Campina Grande, PB, Brasil; cobfilho@gmail.com.

2 Enfermeira, Mestranda em Recursos Naturais, UFCG, Campina Grande, PB, Brasil; julianamvasconcelos@hotmail.com.

3 Engenheiro Químico, Professor Doutor, Centro de Ciências e Tecnologia da Unidade Acadêmica de Engenharia de Materiais, UFCG Campina Grande, PB, Brasil.

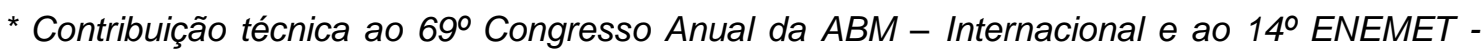
Encontro Nacional de Estudantes de Engenharia Metalúrgica, de Materiais e de Minas, 21 a 25 de julho de 2014, São Paulo, SP, Brasil.
} 


\section{INTRODUÇÃO}

A radiação solar e essencial para a vida na superfície terrestre ela causa bem estar, aquece, ilumina, é fonte de vitamina D, dentre outros benefícios. Embora seja utilizada em diversas áreas, sua componente ultravioleta, pode causar alguns efeitos indesejáveis no organismo humano, tratando-se de uma radiação de alta energia [1].

$A$ radiação ultravioleta e uma parte da radiação solar composta de três faixas, Ultravioleta C (UVC), Ultravioleta B (UVB) e Ultravioleta A (UVA). A radiação UVA atravessa facilmente a camada de ozônio atinge a pele com a mesma intensidade em qualquer horário do dia e época do ano, seja em meses de inverno ou de verão, os raios UVB são parcialmente filtrados na camada de ozônio sendo mais eficiente em produzir danos diretos ao DNA, fotoimunossupressão, espaçamento da camada córnea e melanogênese, sendo considerado o maior fator etiológico das três formas de câncer cutâneo [2-4].

Algumas alterações de pele podem ser causadas ou influenciadas pela luz solar. Tais alterações podem se manifestar na forma de doenças agudas ou crônicas e caracterizam-se por se manifestarem exclusivamente nas áreas foto expostas. Dentre essas doenças pode-se citar: queimaduras solares, fotoenvelhecimento e neoplasias malignas da pele [5].

O uso habitual do protetor solar com Fator de Proteção Solar (FPS) de no mínimo 15, vestimentas, óculos e chapéus são facilmente disponíveis e eficazes para defesa do organismo contra efeitos nocivos da radiação UV. A academia Americana de Dermatologia recomenda o uso de vestimentas apropriadas e óculos escuros para exposição prolongada ao sol, porém alguns tipos de tecidos não proporcionam proteção suficiente [6].

Atualmente, novos tecidos possuem a capacidade de proteção solar elevada, inclusive, alguns apresentam partículas de dióxido de titânio dispersas por entre suas fibras, permitindo proteção combinada UVA e UVB. A incorporação de partículas de filtros solares inorgânicos promove aumento no valor do FPU, Fator de Proteção Ultravioleta. Tecidos clássicos como algodão, podem igualmente ter seu valor de FPU elevado com a incorporação de filtros solares [6].

Os tecidos sintéticos tem despertado interesse em diversas áreas pela capacidade de proteção contras os raios UV, como o caso da poliamida. Estas fibras possuem capacidade de proteção solar diferente das fibras naturais, por exemplo, o algodão. A este tipo de fibra sintética, podem ser incorporadas partículas minerais (ex. dióxido de titânio) com o objetivo de permitir proteção combinada UVA e UVB. A incorporação de partículas de filtros solares inorgânicos promove o aumento no valor do fator de proteção ultravioleta FPU das vestimentas [7].

A fibra de poliamida ou nylon é uma fibra muito forte, que apresenta resultados de propriedades excepcionais, incluindo flexibilidade, estabilidade

dimensional, resistência a abrasão, durabilidade, rigidez, receptividade a corantes, resistência ao calor, capacidade de reciclagem e excelentes propriedades de revestimento [8]. Apresentam uma multiplicidade de usos, desde oferecer conforto para mobílias, estofados, automóveis, carpetes, abrasivos industriais, isolamento elétrico, tecidos, vestuário esportivo, dentre outros. Ultimamente, as fibras de poliamida vêm chamando atenção na confecção de tecidos de proteção contra radiação ultravioleta (UV) [9].

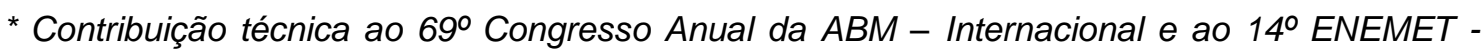
Encontro Nacional de Estudantes de Engenharia Metalúrgica, de Materiais e de Minas, 21 a 25 de julho de 2014, São Paulo, SP, Brasil.
} 
O fator de proteção ultravioleta (FPU) avalia o grau de proteção das vestimentas. Este fator é semelhante ao fator de proteção solar (FPS) aplicado aos protetores solares. Supostamente, representa a proteção tanto contra a radiação UVA quanto contra a radiação UVB, relacionando o tempo de exposição segura ao sol à proteção e ao tempo de exposição sem proteção [10].

Nesta pesquisa serão utilizadas duas amostras de poliamidas, uma com a incorporação de partículas de dióxido de titânio que garante proteção solar e outra sem esse aditivo, no intuito de garantir a eficácia do tecido com a incorporação da partícula foto protetoras contra os foto danos causados pela radiação solar.

A atual pesquisa objetivou analisar através de estudos a eficiência de tecidos foto protetores utilizados contra efeitos nocivos da radiação solar.

\section{MATERIAIS E MÉTODOS}

Na pesquisa foram utilizados: Tecido comercial de poliamida sem proteção na cor branca, adquirido em lojas têxteis na região de João Pessoa - PB. Identificado como tecido comercial I e Tecido de poliamida (vestimenta) na cor branca com certificado da ARPANSA dentro da norma AS/NZS 4399:1996 com FPU $50+$ e bloqueio de $98 \%$ de radiação Ultravioleta (UV). Identificado como tecido comercial II

As amostras de tecidos foram cortadas no tamanho $2 \mathrm{~cm}^{2}$ e caracterizadas por Microscopia Ótica (MO), Microscopia Eletrônica de Varredura (MEV), Espectroscopia por Energia Dispersiva (EDS), Espectroscopia na região do infravermelho com transformada de Fourier (FTIR), Difração de raios X (DRX) e Calorimetria Exploratória de Diferencial (DSC).

\section{RESULTADOS E DISCUSSÃO}

\subsection{Microscopia Ótica (MO)}

A figura 1 apresenta as imagens da microscopia óptica do Tecido Comercial I e Comercial II. É possível notar que as duas amostras apresentam estruturas morfológicas bem definidas. Igualmente, percebe-se que a amostra Comercial I apresenta poros dispostos de forma contínua e, na amostra Comercial II, constata-se um entrelaçamento das fibras com alternância dos poros.

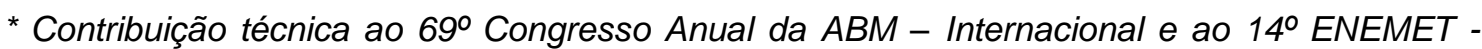
Encontro Nacional de Estudantes de Engenharia Metalúrgica, de Materiais e de Minas, 21 a 25 de julho de 2014, São Paulo, SP, Brasil.
} 

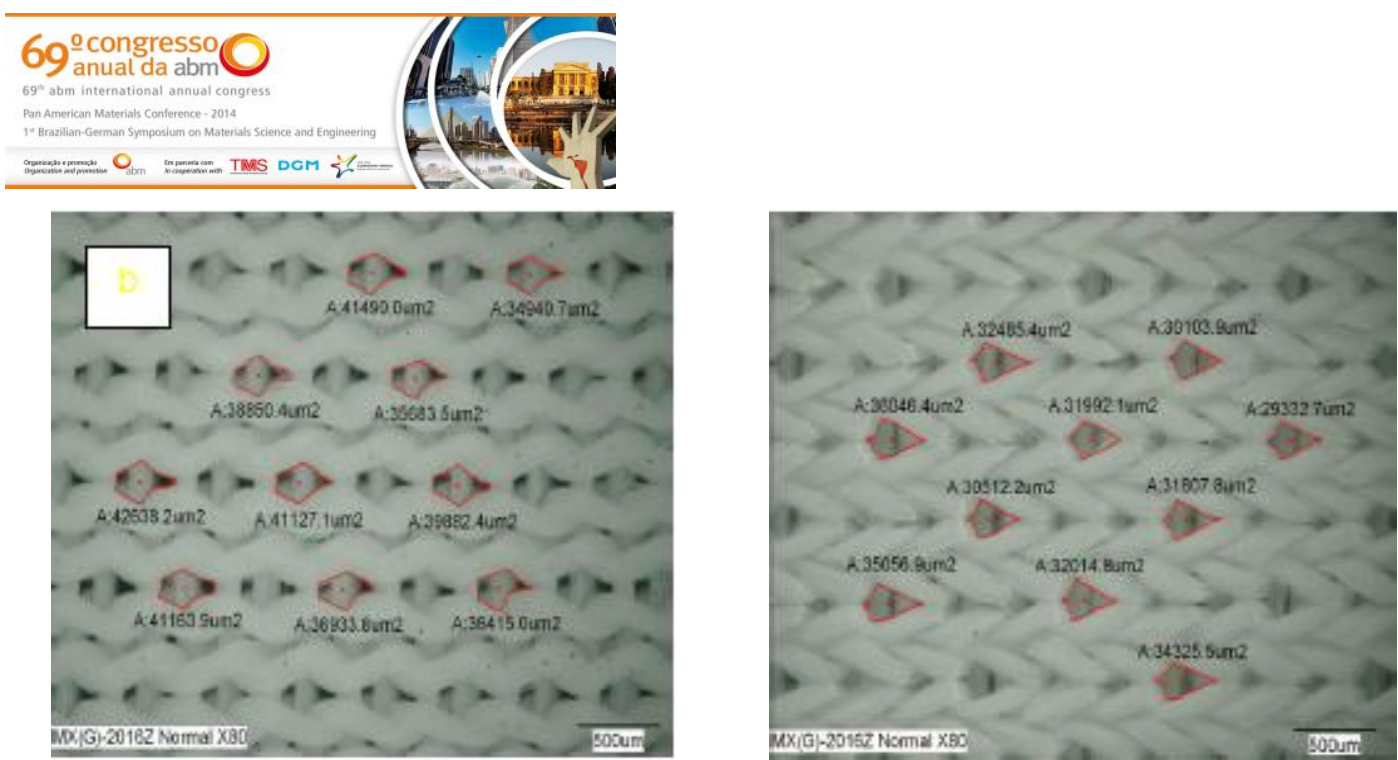

Figura 1: Microscopia Ótica das amostras de tecidos (a) Comercial le (b) Comercial II

De acordo com a Tabela 1, e possível observar que a amostra Comercial I apresenta tamanho médio de poros superior quando comparado à amostra Comercial II representando um tamanho médio superior na amostra Comercial I de $22,62 \%$ maior que na amostra Comercial II. Quanto ao processo de entrelaçamento dos fios para fabricação do tecido, nota-se que as duas amostras de tecidos apresentam características de tecido tipo malha.

Tabela 1 : Tamanho médio dos poros das amostras Comercial I e Comercial II.

\begin{tabular}{cc}
\hline Amostra & Tamanho médio dos poros \\
\hline Comercial I & $39.366 \mu \mathrm{m}^{2}$ \\
\hline Comercial II & $32.104 \mu \mathrm{m}^{2}$ \\
\hline
\end{tabular}

\subsection{Microscopia Eletrônica de Varredura (MEV)}

Ao analisar a morfologia dos tecidos e possível observar dois aspectos importantes: a quantidade média do numero de fios de cada fibra e a presença de partículas na amostra Comercial II.

Observando a ampliação das figuras 2 e 3, é possível identificar que o número de fios na amostra Comercial II é superior quando comparada a amostra comercial I, indicando que a segunda amostra apresenta maior densidade têxtil. Ainda observando a amostra Comercial II, é possível identificar a presença de partículas esféricas distribuídas entre as fibras do tecido que podem ser atribuídas ao aditivo dióxido de titânio.

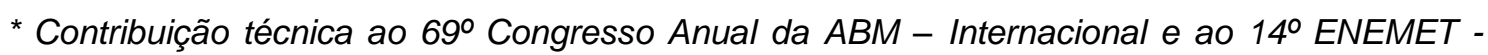
Encontro Nacional de Estudantes de Engenharia Metalúrgica, de Materiais e de Minas, 21 a 25 de julho de 2014, São Paulo, SP, Brasil. 

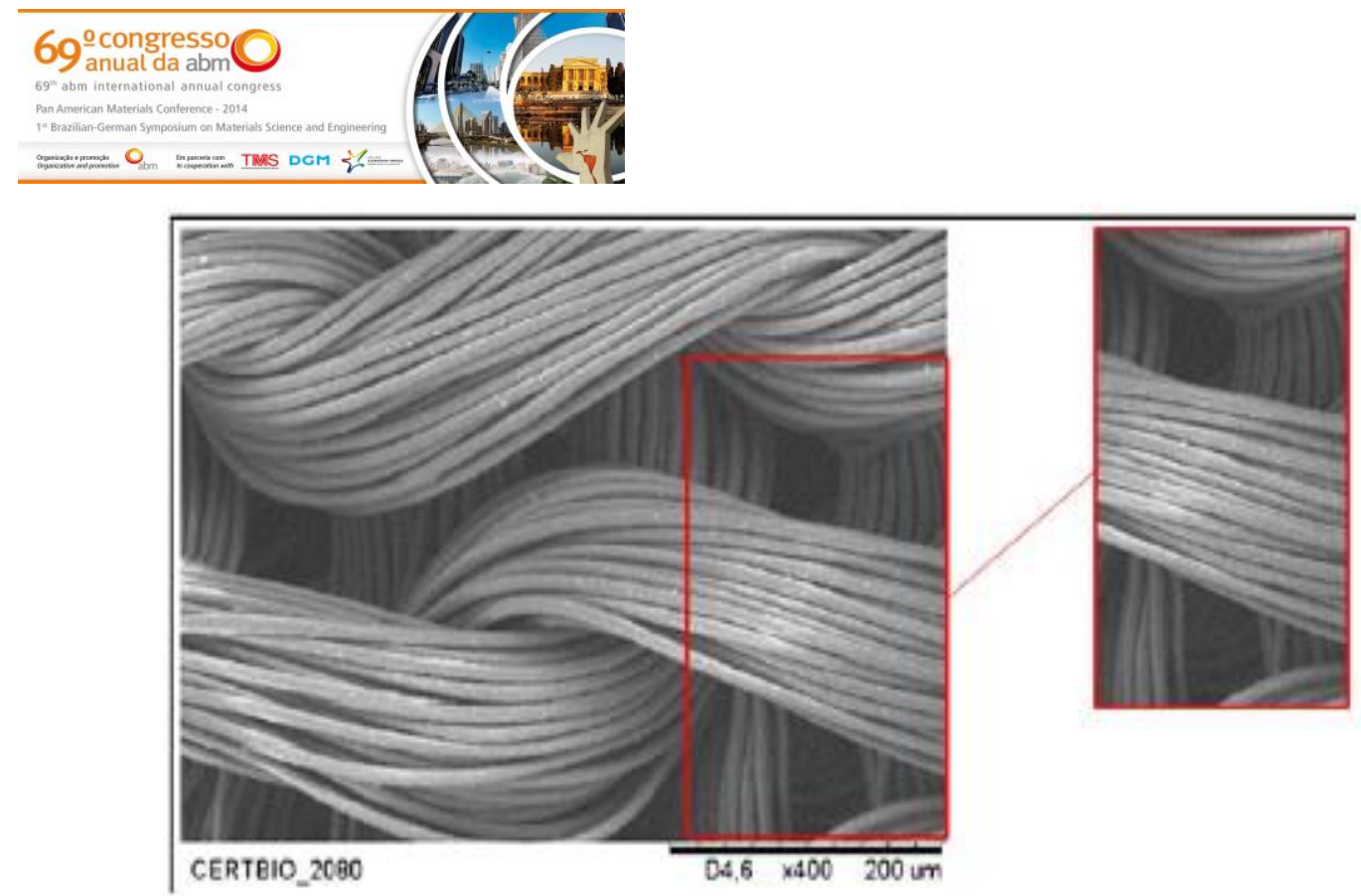

Figura 2: Microscopia Eletrônica de Varredura (MEV) da amostra de tecido Comercial I - x 400.

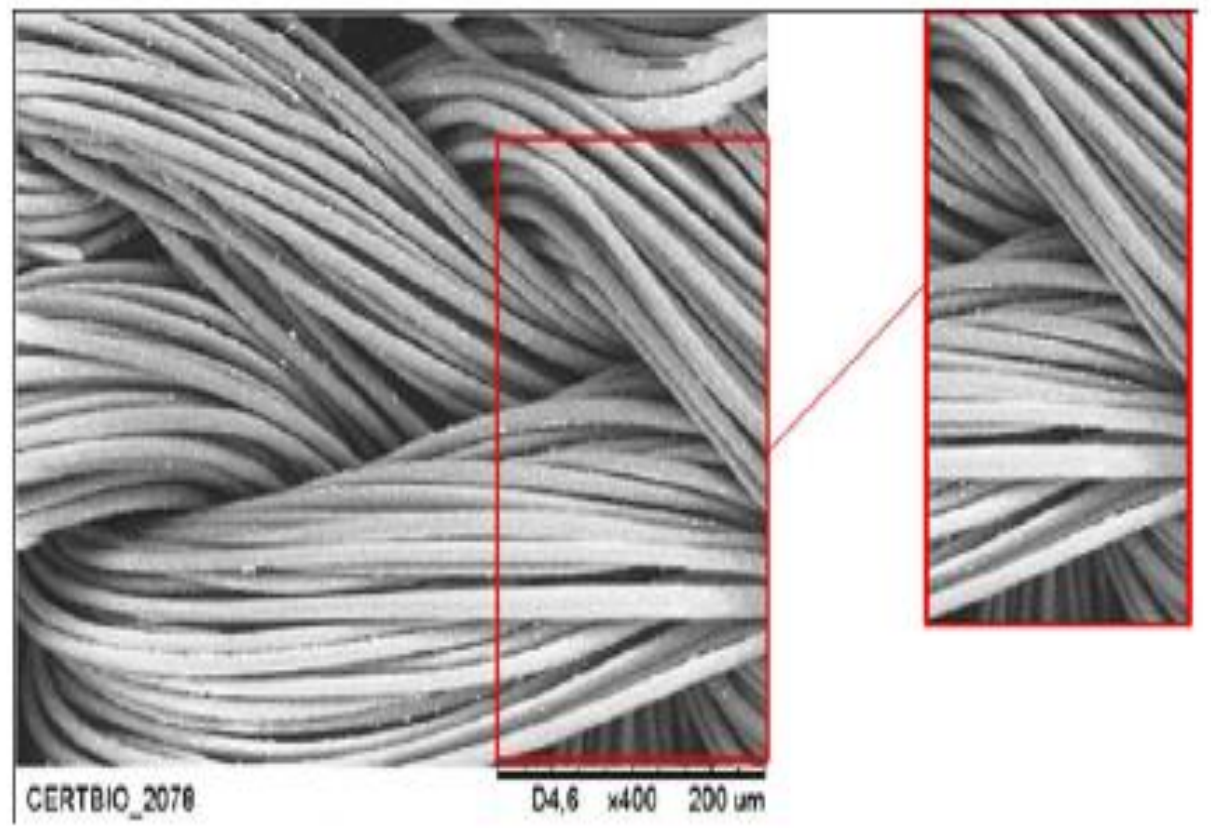

Figura 3: Microscopia Eletrônica de Varredura (MEV) da amostra de tecido Comercial II

\subsection{Espectroscopia por Energia Dispersiva (EDS)}

$\mathrm{Na}$ figura 4 observa-se, no espectro de EDS, a presença dos elementos carbono, oxigênio, nitrogênio e titânio nas duas amostras de tecido. Os elementos carbono, oxigênio e nitrogênio já eram esperados de ser detectados, pois estão presentes na estrutura da poliamida. A identificação $\left(\mathrm{TiO}_{2}\right)$ nas duas amostras, pode estar associada a introdução destes na forma de pigmento (corante) para conferir a cor branca do tecido.

* Contribuição técnica ao 69ํㅡㄹ Congresso Anual da ABM - Internacional e ao 14ํ ENEMET Encontro Nacional de Estudantes de Engenharia Metalúrgica, de Materiais e de Minas, 21 a 25 de julho de 2014, São Paulo, SP, Brasil. 

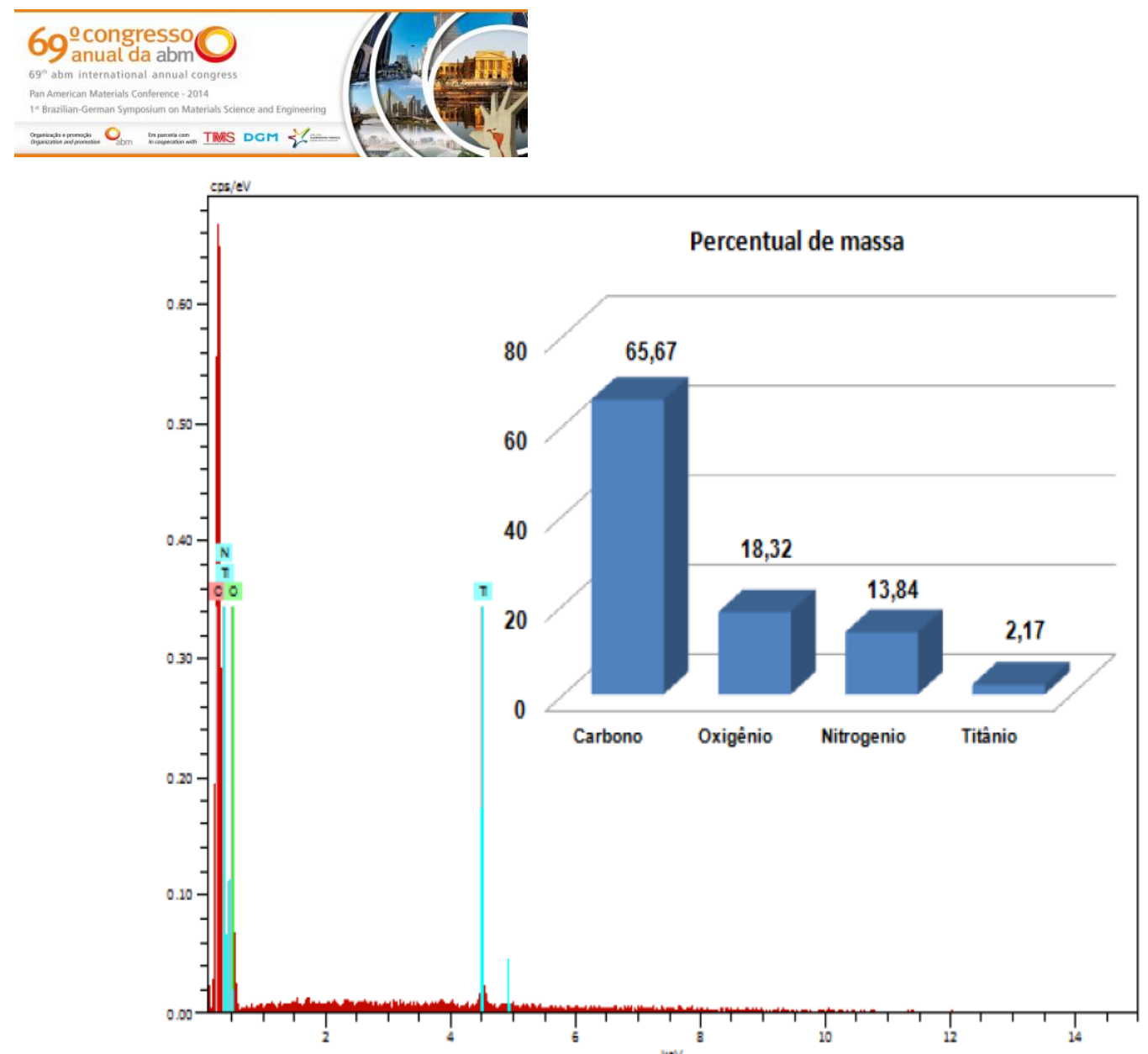

(a) Comercial I

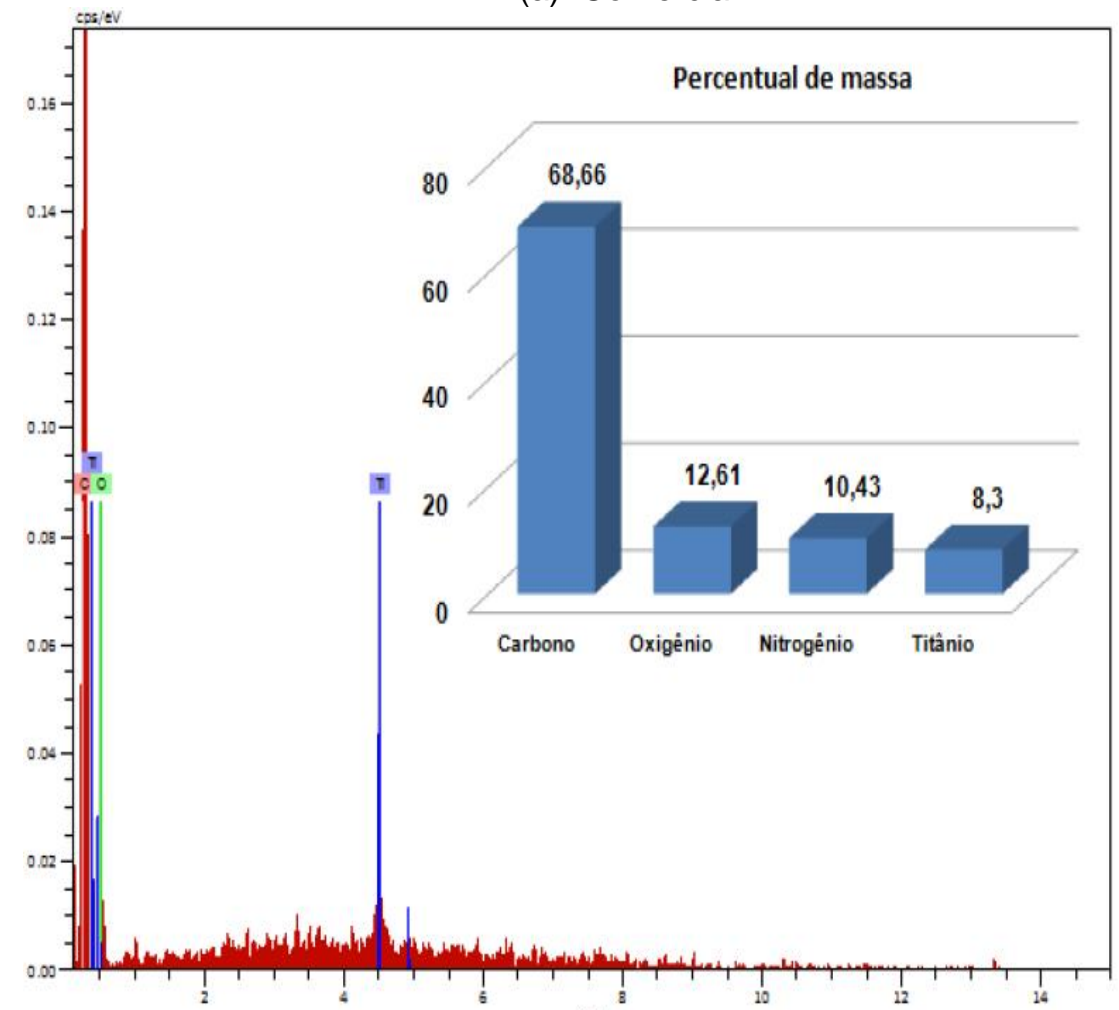

(b) Comercial II

Figura 4: Espectroscopia por Energia Dispersiva (EDS) das amostras do tecido (a) Comercial I e (b) Comercial II.

Foi possível observar que a amostra Comercial II apresentou percentual de titânio (aproximadamente 8\%) superior quando comparada a amostra comercial

* Contribuição técnica ao 69ํ Congresso Anual da ABM - Internacional e ao $14^{\circ}$ ENEMET Encontro Nacional de Estudantes de Engenharia Metalúrgica, de Materiais e de Minas, 21 a 25 de julho de 2014, São Paulo, SP, Brasil. 


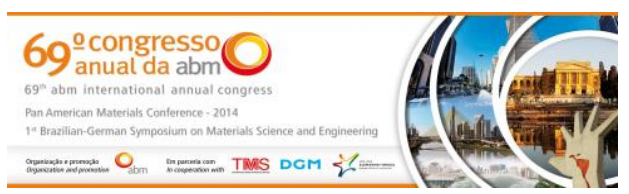

I (aproximadamente $2 \%$ ), pois de acordo com o fabricante da amostra comercial $\mathrm{Il}, \mathrm{o} \mathrm{TiO}_{2}$ foi incorporado ao tecido para auxiliar na defesa do organismo contra os efeitos nocivos da radiação UV. Entretanto ao compararmos os dois tecidos, observamos uma concentração de titânio 3, 8 vezes superior no tecido Comercial II em relação ao tecido Comercial I.

\subsection{Difração de Raio X (DRX)}

A figura 5 apresenta o difratograma de raios $X$ das amostras do tecido Comercial I e Comercial II.

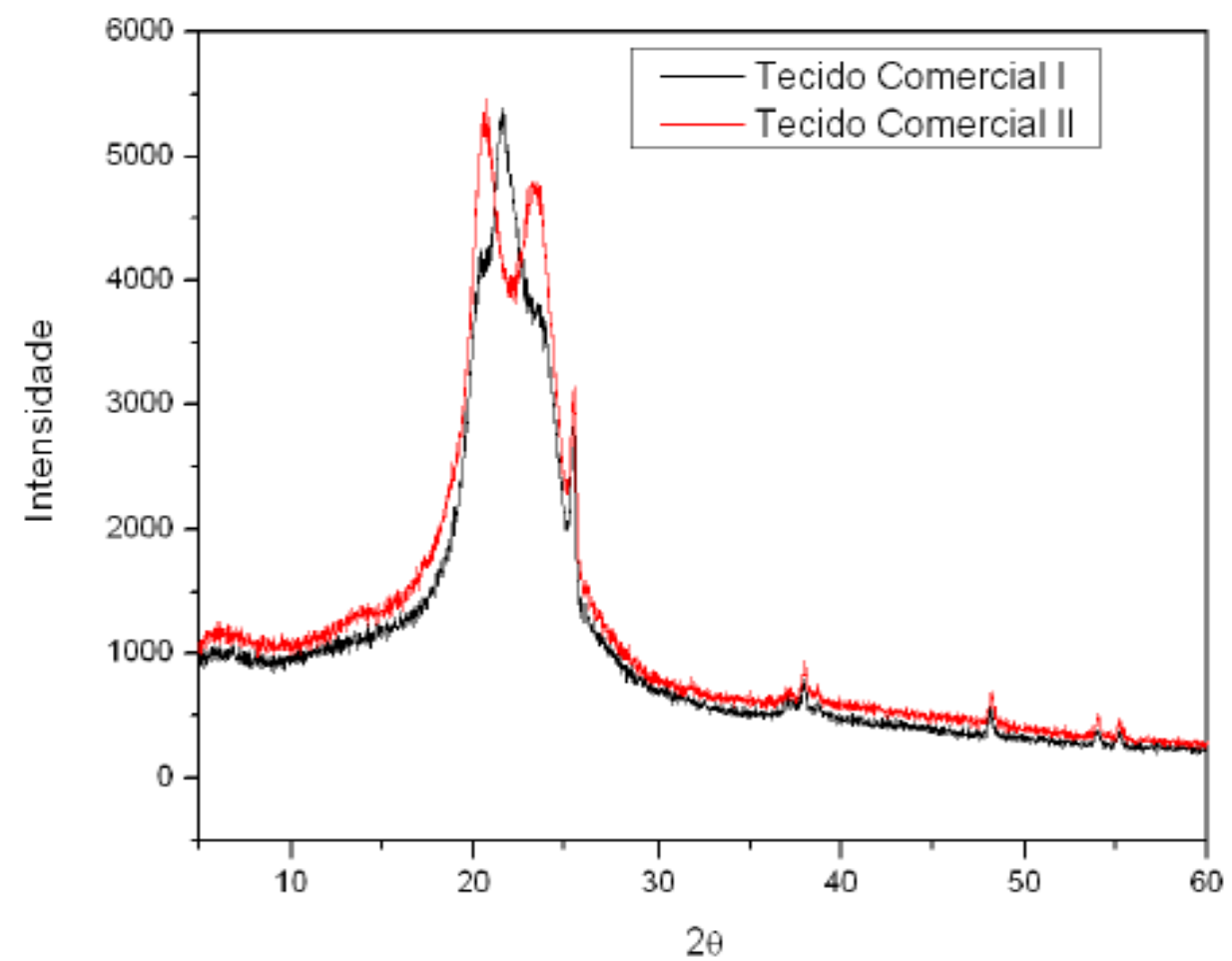

Figura 5: Difratograma de raios $\mathrm{X}$ das amostras de tecido Comercial I e Comercial II.

Através do difratograma, é possível observar a semelhança de intensidade e sobreposição dos picos entre as duas amostras de tecido, exceto o pico em aproximadamente $25^{\circ}$ (difração de $2 \theta$ ) do Tecido Comercial II. Esse pico está associado a presença do dióxido de titânio (TiO2) na fase anatásio, correspondendo ao plano (101) (ficha 21-1272), que evidencia a estrutura cristalina do $\mathrm{TiO} 2$ com ação foto protetora mais efetiva.

\subsection{Espectroscopia na Região do Infravermelho com Transformada de Fourier (FTIR)}

O espectro de infravermelho obtido das amostras Comercial I e Comercial II está apresentado na figura 6 . Os picos na faixa de 2800 a $3000 \mathrm{~cm}^{-1}$ são característicos dos estiramentos simétricos e assimétricos $\mathrm{C}-\mathrm{H}$ das cadeias carbônicas, enquanto que o pico em torno de $3300 \mathrm{~cm}^{-1}$ pode ser atribuído ao estiramento $\mathrm{N}-\mathrm{H}$ dos grupamentos amidas de poliamidas. Por outro lado, a presença desses grupos leva ao aparecimento de bandas de estiramento e

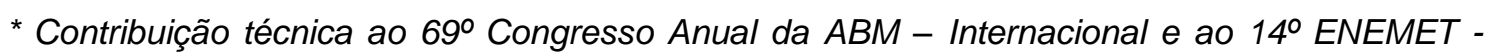
Encontro Nacional de Estudantes de Engenharia Metalúrgica, de Materiais e de Minas, 21 a 25 de julho de 2014, São Paulo, SP, Brasil. 
deformação angular característicos na região de 1000 a $1500 \mathrm{~cm}^{-1}$. O pico entre 700 e $550 \mathrm{~cm}^{-1}$ é característico do $\mathrm{TiO}_{2}$ na forma cristalina anatásio, destaca-se, entretanto a nítida diferença de intensidade entre a amostra de Tecido Comercial II e Tecido Comercial I, evidenciando mais uma vez a diferença entre os dois tecidos.

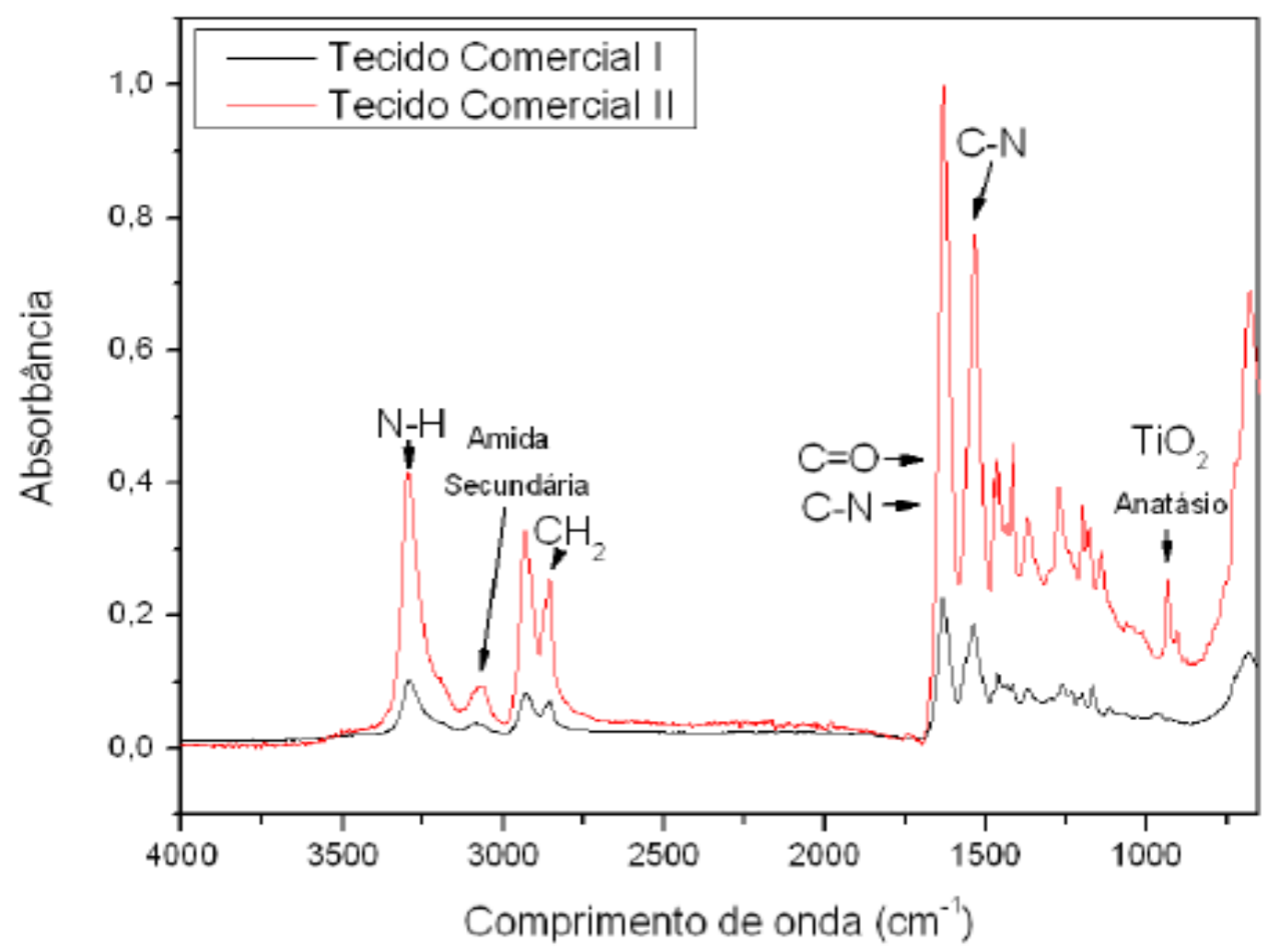

Figura 6: Espectro vibracional do infravermelho das amostras de tecido Comercial I e Comercial II.

\subsection{Caloria Exploratória Diferencial (DSC)}

A figura 7 mostra as curvas de DSC para amostras de tecido (a) Comercial I e (b) Comercial II.

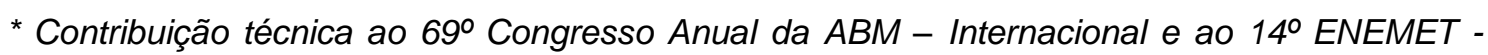
Encontro Nacional de Estudantes de Engenharia Metalúrgica, de Materiais e de Minas, 21 a 25 de julho de 2014, São Paulo, SP, Brasil. 

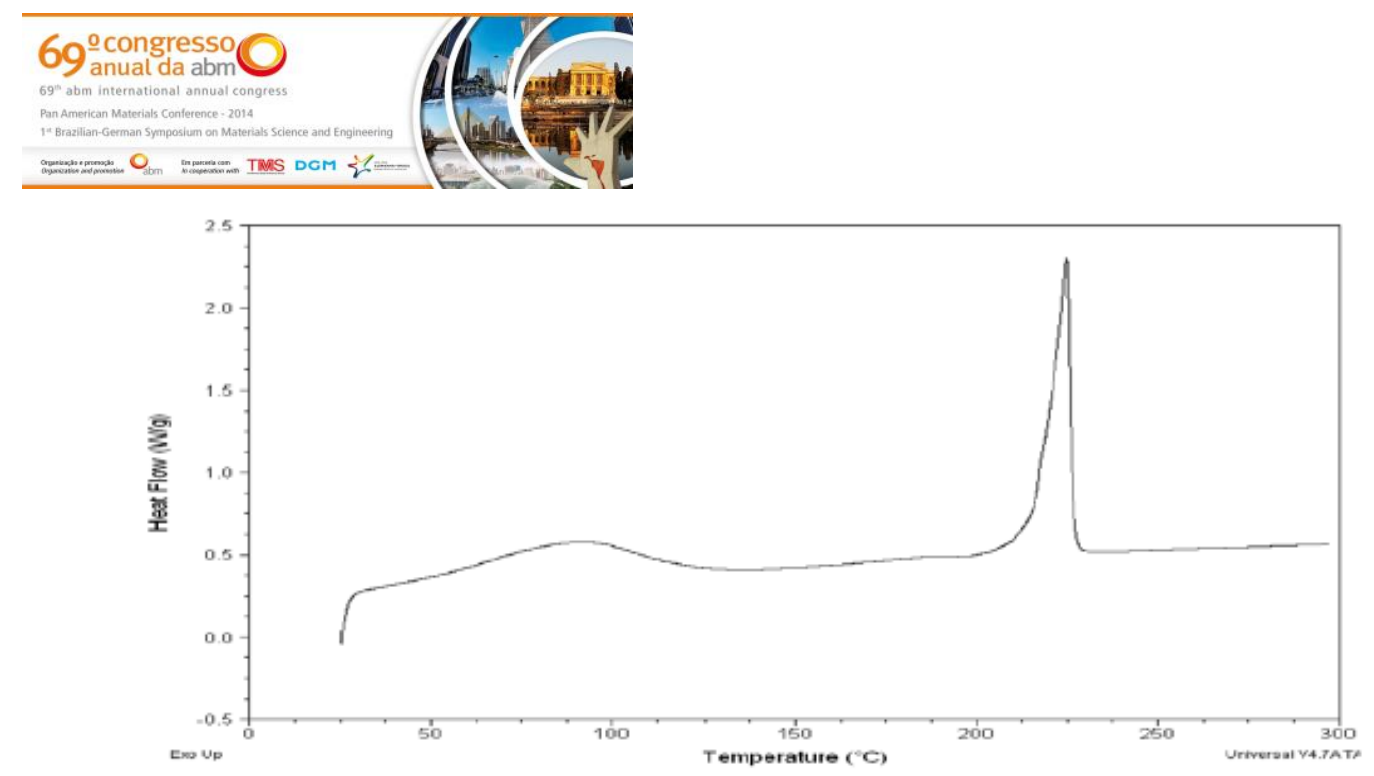

(a)

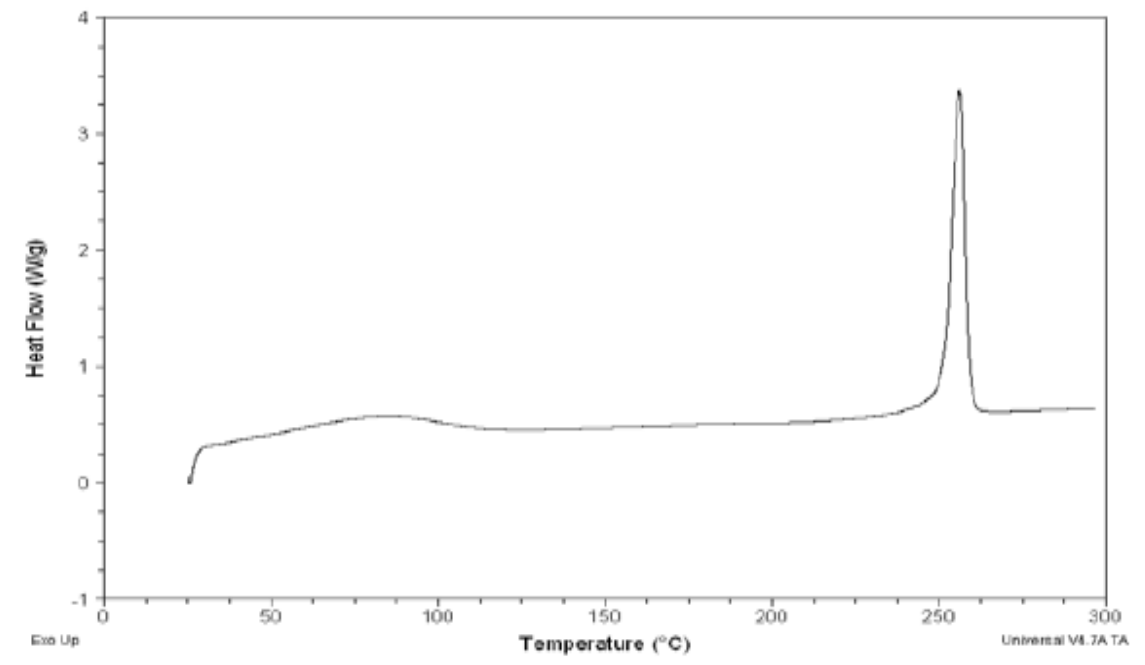

(b)

Figura 7: Curvas de DSC para as amostras de tecido (a) Comercial I e (b) Comercial II.

É possível observar que a $\mathrm{Tg}$ das amostras não mostra um pico bem definido, mas bandas que se situa em valores entre 80 e $92^{\circ} \mathrm{C}$ para ambas as amostras. A amostra Comercial I apresenta um pico de fusão por volta de $225^{\circ} \mathrm{C}$, enquanto a amostra Comercial II apresenta pico de fusão em aproximadamente $260^{\circ} \mathrm{C}$. Dessa forma, podemos observar que há uma grande diferença na temperatura de fusão entre os dois tecidos, dando indícios que a amostra Comercial I e a Comercial II se tratam de uma poliamida 6 e poliamida 6,6, respectivamente. A Tabela 2 mostra de forma resumida os valores da temperatura de cada amostra. Quanto a temperatura de transição vítrea os valores são típicos de uma poliamida 6 e, as variações determinadas entre cada uma das amostras de tecidos Comercial podem ser atribuídas ao processamento do material.

Tabela 2: Temperatura de Transição Vítrea (Tg) e Temperatura de Fusão (Tm) das amostras Comercial I e Comercial II.

\begin{tabular}{ccc}
\hline Amostras/Temperaturas & $\mathrm{Tg}\left({ }^{\circ} \mathrm{C}\right)$ & $\mathrm{Tm}\left({ }^{\circ} \mathrm{C}\right)$ \\
\hline Comercial I & $\sim 88-92$ & $\sim 225$ \\
\hline Comercial II & $\sim 80-88$ & $\sim 260$ \\
\hline
\end{tabular}

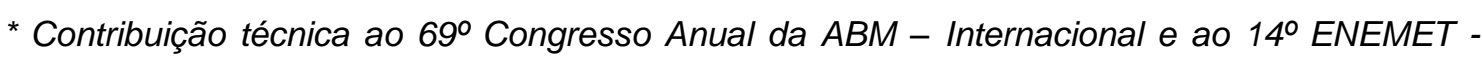
Encontro Nacional de Estudantes de Engenharia Metalúrgica, de Materiais e de Minas, 21 a 25 de julho de 2014, São Paulo, SP, Brasil. 


\section{CONCLUSÃO}

A partir dos resultados obtidos fica estabelecida a eficiência dos tecidos com propriedades foto protetora, na ação efetiva contra os efeitos nocivos da exposição solar. Tal evidência se dá pelo fato de ter sido constatado que a amostra Comercia II reduz a penetração da radiação UV, por possuir maior número de fios indicando maior densidade têxtil, apresenta partículas distribuídas entre as fibras do tecido que são atribuídas ao agente foto protetor, dióxido de titânio, foi também constatado que o percentual de titânio do tecido comercial II é de aproximadamente 3,8 vezes superior que o tecido comercial I. Os elementos carbono, oxigênio e nitrogênio também foram identificados constatando que se trata de uma poliamida.

\section{Agradecimentos}

Os autores gostariam de agradecer ao Laboratório de Desenvolvimento e Avaliação de Biomateriais do Nordeste (CERTBIO), na Universidade Federal de Campina Grande - UFCG, pela realização dos experimentos.

\section{REFERÊNCIAS}

1 Okuno E, Vilela MAC. Radiação ultravioleta: características e efeitos, Editora Livraria da Fisica, $1^{\circ}$ ed. 2005.

2 Costa F, Weber MB. Avaliação dos hábitos de exposição ao sol e de fotoproteção dos universitários da Região Metropolitana de Porto Alegre, RS. Anais Brasileiros de Dermatologia, Rio de Janeiro, 2004; 79(2): 149-155.

3 Bezerra SMFMC. Efeitos da radiação solar crônica e prolongada sobre o sistema imunológico de pescadores de recife. 2007. 129 f. Tese (Doutorado) - Curso de Medicina, Departamento de Medicina, Universidade de São Paulo, São Paulo, 2007.

4 Both, G. C., Centro de Informações Hidrometeorológicas (CIH) - UNIVATES, Radiação Ultravioleta: um inimigo invisível. Disponível em: http://www.biofisica.ufsc.brindex.jsppage=arquivos/radiacao.htm. Acesso: 24/09/12.

5 Zotelli I. Doenças de pele causadas pelo sol. APM, Piracicaba, 2012; 7(64): 6-7.

6 Balogh TS, et al. Proteção à radiação ultravioleta: recursos disponíveis na atualidade em fotoproteção. Anais Brasileiros de Dermatologia. Rio de Janeiro, V. 86, n. 4, p. 732-742, 2011.

7 Baron ED, Kirkland EB, Domingo DS. Advances in photoprotection. Dermatol Nurs. V. 20, p-265-7, 2008.

8 Araujo M, Castro EMM. Manual de Engenharia Têxtil, Editora Fundacao Calouste Gulbenkien, Lisboa, v. 1, 1984

9 Valente AC, Oliveira R. Poliamida: solidez da cor para o desenvolvimento da indústria, Revista da Unifebe, p. 1-17, 2011.

10 Palm MD, O'donoghue MN. Update on photo protection. Dermatol Ther. 2007;20:76-360.

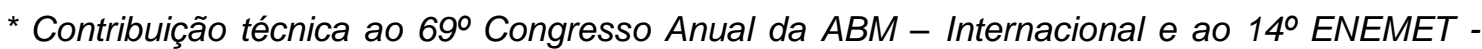
Encontro Nacional de Estudantes de Engenharia Metalúrgica, de Materiais e de Minas, 21 a 25 de julho de 2014, São Paulo, SP, Brasil.
} 